\title{
A MULTIVARIATE STATISTICAL ANALYSIS APPROACH FOR THE ASSESSMENT OF WATER QUALITY IN GOVIND BALLABH PANT SAGAR RESERVOIR
}

\author{
Ramita Varshney* and Aarif Jamal \\ Department of Mining Engineering, Indian Institute of Technology (Banaras Hindu University), \\ Varanasi-221005, India \\ *E-mail: ramita25j@gmail.com
}

\begin{abstract}
Reservoir water is one of the essential sources of water which plays a significant part in not only contributing a sufficient supply of water for industrial operations but it also acts as a source of drinking water. Therefore, contamination of it through industrial, irrigational or any other human intervention can pose a serious threat to it both qualitatively and quantitatively. In the present study, 14 physicochemical parameters of eight sampling sites served as the attribute database represented in form of the correlation matrix for each parameter taking participation in the study. Apart from this, the Water Quality Index of the sampling sites has been enumerated by combining these physicochemical parameters. Hierarchical Cluster Analysis was also performed for grouping the areas having similar grading of water quality index. The overall results indicate that most of the sampling sites were not suitable for drinking purpose and requires treatment of water before use.

Keywords: Reservoir water, Hierarchical Cluster Analysis, Correlation matrix, Water quality, Water Quality Index.
\end{abstract}

(C) RASĀYAN. All rights reserved

\section{INTRODUCTION}

Surface water bodies such as rivers, lakes, reservoirs, etc. have a pivotal part in maintaining the water cycles. ${ }^{1}$ Surface water is one of the most essential sources which couldn't be used appropriately unless its quality is properly analyzed. Due to the prolific rise in population, commercialization and socio-urban expansion the demand water has increased tremendously. The surface water quality is, however, is deteriorating due to exaggerated use of petrochemical fertilizers, inadequate planning, use of high concentration of organic and inorganic substances, improper sewage management or direct discharge of industrial waste into the nearby water body.

Coal mining is one of the major industries of India thereby playing a major role in the economy of the country on one hand while deteriorating environment on the other hand..$^{2-3}$ According to the annual report of Coal India Limited for the financial year 2016-17, there are 176 opencast and 310 underground coal mines operating in India, thereby contributing approximately 60.6 billion tonnes of coal annually. ${ }^{4}$ The excavation, refining and processing of coal lead to changes in the environment and affecting the water of nearby area either directly or indirectly at each level.

The mining industry is one of such industries in India which utilizes a large amount of water and generates a huge volume of waste during its processing. This causes the change in both the quality and quantity of water surrounding the coal mines.

Therefore, the present study mainly focuses on the estimation of the water quality index (WQI) along with correlation analysis of physicochemical parameters and WQI followed by computation of Hierarchical Cluster Analysis (HCA) in form of dendrogram generated from WQI of the samples collected from various sites of Govind Ballabh Pant Sagar Reservoir. The evaluation of the acceptability of water for drinking, irrigation and industrial purpose was analyzed by comparing the parameters with drinking water quality standards as prescribed by World Health Organization (WHO) ${ }^{5}$ and Bureau of Indian Standards (BIS). ${ }^{6}$

Rasayan J. Chem., 12(1), 251-256(2019)

http://dx.doi.org/10.31788/RJC.2019.1215056

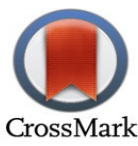




\section{Study Area}

The area under study i.e. G.B. Pant Sagar Reservoir lies in Singrauli region which lies at the border of Uttar Pradesh (Sonebhadra District) and Madhya Pradesh (Sidhi and Surguja District). This area is known as the energy capital of India with rich reserves of coal in it ${ }^{7}$. The presence of G.B. Pant Sagar reservoir was the root cause for the establishment of many power plants around it. The study area lies between $24^{\circ}$ to $24^{\circ} 12^{\prime}$ North latitude and $82^{\circ} 38^{\prime}$ to $83^{\circ} 5^{\prime}$ East longitude ${ }^{10}$. The reservoir has a capacity of 10625 cubic million meters at the Full Reservoir Level (FRL) of $268 \mathrm{~m}$ above mean sea level with an estimated annual rate of inflow of around 6301 cubic million meter ${ }^{8}$. The regional geology comprises Quartzite, Phyllite and Schist as a part of Precambrian metamorphic formation whereas the part representing Gondwana Formation comprises of Shale and Sandstone. About 7500MW of electricity is being generated by the five Thermal Power Plant present around it.

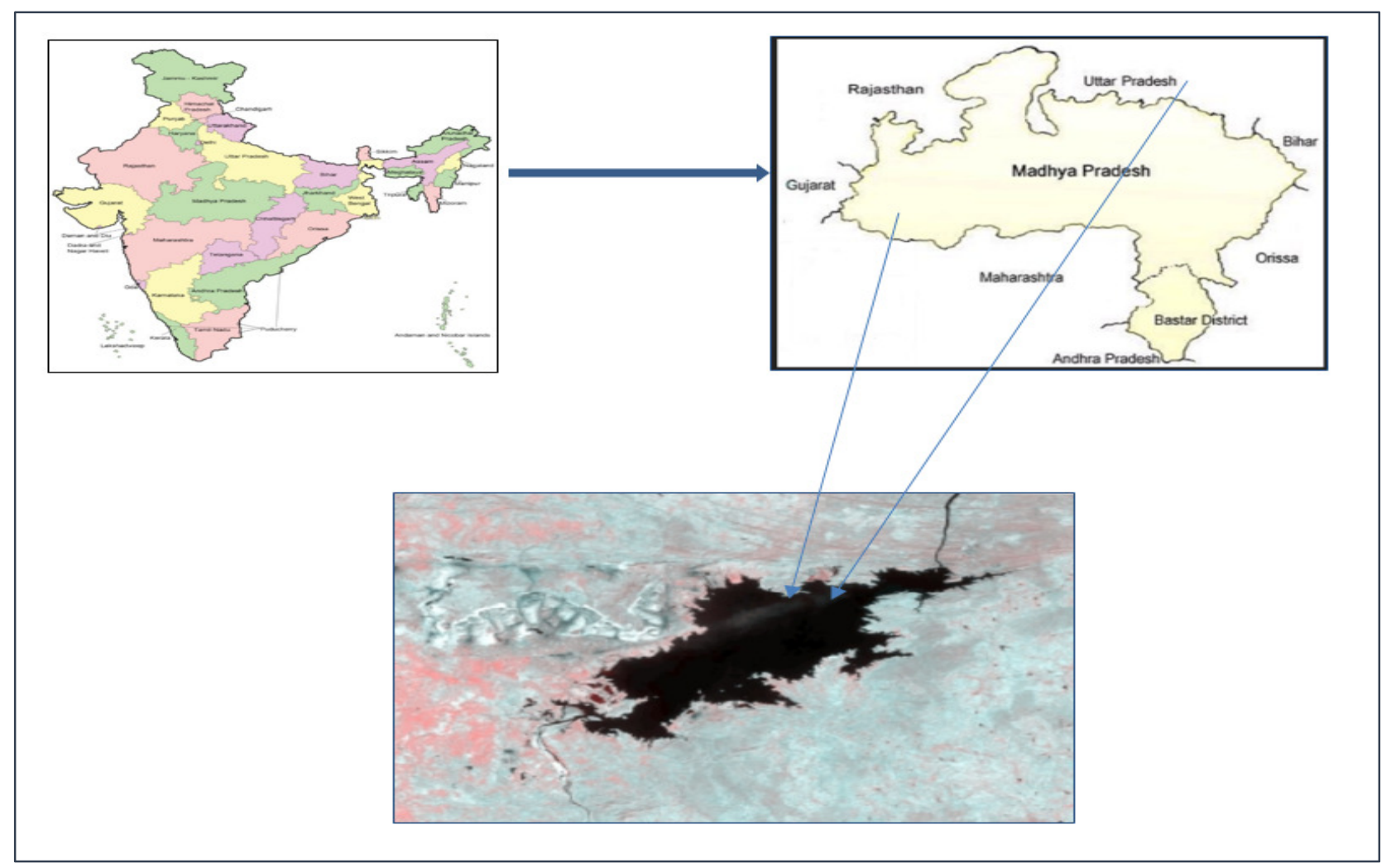

Fig.-1: Location Map of Study Area

The climatic pattern of the study area is indicated by considerable variation in temperature and rainfall. The area is characterized by high rainfall and humidity followed by low-temperature fluctuation. The average annual maximum and minimum temperatures are about $37^{\circ} \mathrm{C}$ and $20^{\circ} \mathrm{C}$ respectively. Around 11 Opencast coal mines are being operated by Northern Coalfield Limited in the proximity of the reservoir.

\section{EXPERIMENTAL}

To attain the objective of the study, eight sampling sites around G. B. Pant Sagar Reservoir were chosen after proper preliminary field survey. The sampling was done in clean, sterile polypropylene wide mouth reagent bottle of $125 \mathrm{ml}$, immediately acidified to $\mathrm{pH}$ less than 2 with nitric acid and stored with necessary precautions at a temperature $<4^{\circ} \mathrm{C}$ in the laboratory to refrain any chemical alterations. For the analysis of physiochemical characteristics, the samples were collected around 9-12 o'clock, during the third week of February. During the monitoring campaign of the study area, some in-situ measurements of samples such as pH, Electrical Conductivity (EC), Total Dissolved Solids (TDS), Dissolved Solids (DO) and Temperature were conducted using well calibrated Hanna Hi 9828 multi-parameter apparatus. The samples were then analyzed for other cations and anions in the Institute laboratory using Ion 
RASĀYAN J. Chem.

Vol. 12 | No. 1 |251 - 256| January - March | 2019

Chromatography. Ultrapure water with a resistivity of $18.2 \mathrm{M} \Omega \mathrm{cm}$ was used as a blank for all the analysis. The remaining physicochemical parameters such as Total Suspended Solids (TSS), Hardness etc. were measured and calculated in the departmental laboratory using the standard prescribed technique as laid down in 'Standard Methods for the examination of water and wastewater (APHA 2012)'12.

After this water quality index (WQI) was determined for all the samples collected in order to determine the suitability of it in domestic or drinking purposes using Weighted Arithmetic Water Quality Index formula as given by Brown et al $(1972)^{11}$. WQI $=\sum \mathrm{Q}_{\mathrm{i}} \mathrm{W}_{\mathrm{i}} / \sum \mathrm{W}_{\mathrm{i}}$ where $\mathrm{W}_{\mathrm{i}}$ represents the relative weight of each parameter while $\mathrm{Q}_{\mathrm{i}}$ represents Quality rating for each parameter. The values acquired for WQI is further classified into 5 important grading as shown in Table-1.

Table-1: Water Quality Rating as per Weighted Arithmetic Water Quality Index Method ${ }^{14}$

\begin{tabular}{c|c|c|c}
\hline S. No. & WQI Value & Rating of Water Quality & Grading \\
\hline 1 & $0-25$ & Excellent Water Quality & A \\
\hline 2 & $25-50$ & Good Water Quality & B \\
\hline 3 & $51-75$ & Poor Water Quality & C \\
\hline 4 & $76-100$ & Very Poor Water Quality & D \\
\hline 5 & Above 100 & Unsuitable for drinking purpose & E \\
\hline
\end{tabular}

All the data were subjected to multivariate statistical analysis using XLSTAT and Microsoft Excel 2010 for computation of correlation matrix and Hierarchical cluster analysis for obtaining Dendrogram. These statistical techniques are useful since the association of these variables shows the coherence as well as the influence of each chemical parameter in influencing the other several chemical properties of the datase ${ }^{15}$. Other than this, these are also used to analyze the similarity of WQI variation tendencies found in the selected sites of the study area.

\section{RESULTS AND DISCUSSION}

The concept of water quality Index helps in understanding the issues related with the quality of water by incorporating numerous physicochemical parameters of a sample and generating a single numerical value thereby representing the status of the water quality of a particular sampling site. In the present study, WQI has been calculated as per the drinking water standards are given by WHO and BIS. The results of which have been tabulated in Table-2. It can be computed from the table that WQI varies from 81.76 to 11.48 for the eight sampling sites denoted as $\mathrm{S}-1,2,3,4,5,6,7$ and 8 thereby representing them from very poor to excellent grade as shown in Fig.-2.

Table-2: Physico-chemical Characterization along with Water Quality Index (WQI) of samples of Govind Ballabh Pant Sagar Reservoir with $\mathrm{K}=2.065$ and $\sum \mathrm{W}_{\mathrm{i}}=1.0320$

\begin{tabular}{|c|c|c|c|c|c|c|c|c|c|}
\hline Sample Location & S-1 & S-2 & S-3 & S-4 & S-5 & S-6 & S-7 & S-8 & $\begin{array}{l}\text { Permissible } \\
\text { limit by }\end{array}$ \\
\hline $\begin{array}{ll}\text { Parameters } & \downarrow \\
& \end{array}$ & & & & & & & & & $\begin{array}{l}\text { WHO and BIS } \\
\left(\mathrm{S}_{\mathrm{i}}\right)\end{array}$ \\
\hline $\mathrm{pH}$ & 7.15 & 7.48 & 6.87 & 7.28 & 8.82 & 7.28 & 7.1 & 7.3 & $6.5-8.5$ \\
\hline $\begin{array}{l}\text { Electrical } \\
\text { Conductivity(EC) }\end{array}$ & 656 & 679 & 117 & 120 & 77 & 214 & 138 & 137 & 300 \\
\hline $\begin{array}{l}\text { Total Dissolved } \\
\text { Solids (TDS) }\end{array}$ & 328 & 340 & 58 & 60 & 38 & 107 & 69 & 69 & 500 \\
\hline $\begin{array}{l}\text { Total Suspended } \\
\text { Solids (TSS) }\end{array}$ & 197 & 186 & 345 & 189 & 173 & 172 & 163 & 79 & 500 \\
\hline $\begin{array}{l}\text { Dissolved Oxygen } \\
\text { (DO) }\end{array}$ & 4.99 & 4.93 & 5.66 & 4.64 & 4.67 & 4.72 & 5.15 & 5.4 & $>5$ \\
\hline Chloride & 24 & 20 & 4.28 & 4.29 & 2.40 & 5.35 & 5.44 & 5.73 & 250 \\
\hline Bicarbonate & 104 & 113 & 35 & 39 & 14 & 56 & 39 & 41 & 200 \\
\hline Calcium & 59.8 & 68 & 11.01 & 10.45 & 7.84 & 20.34 & 11.14 & 12.49 & 75 \\
\hline Magnesium & 22.8 & 25 & 4.6 & 4.2 & 1.48 & 8.7 & 5.13 & 5.71 & 30 \\
\hline Sulphate & 329 & 377 & 10.2 & 10.04 & 21.9 & 11.2 & 13.1 & 14.3 & 150 \\
\hline
\end{tabular}


RASĀYAN J. Chem.

Vol. 12 | No. 1 | 251 - 256| January - March | 2019

\begin{tabular}{l|l|l|l|l|l|l|l|l|l}
\hline Sodium & 47.5 & 50 & 8.2 & 9.5 & 2.59 & 15.75 & 12.52 & 9.95 & 200 \\
\hline Nitrate & 9 & 6 & 1.79 & 1.29 & 1.58 & 1.16 & 0.495 & 0 & 45 \\
\hline Potassium & 21 & 20 & 2.25 & 0 & 3.73 & 2.67 & 2.65 & 2.79 & 15 \\
\hline Total Hardness & 243 & 269 & 46.4 & 43.4 & 25.7 & 86.6 & 48.9 & 54.6 & 300 \\
\hline$\sum \mathrm{Q}_{\mathrm{i}} \mathrm{W}_{\mathrm{i}}$ & 78.55 & 84.37 & 41.23 & 49.48 & 77.2 & 56.61 & 46.99 & 11.85 & ----- \\
\hline$\sum \mathrm{WQI}$ & 76.11 & 81.76 & 39.95 & 47.96 & 74.8 & 54.86 & 45.54 & 11.48 & ----- \\
\hline
\end{tabular}

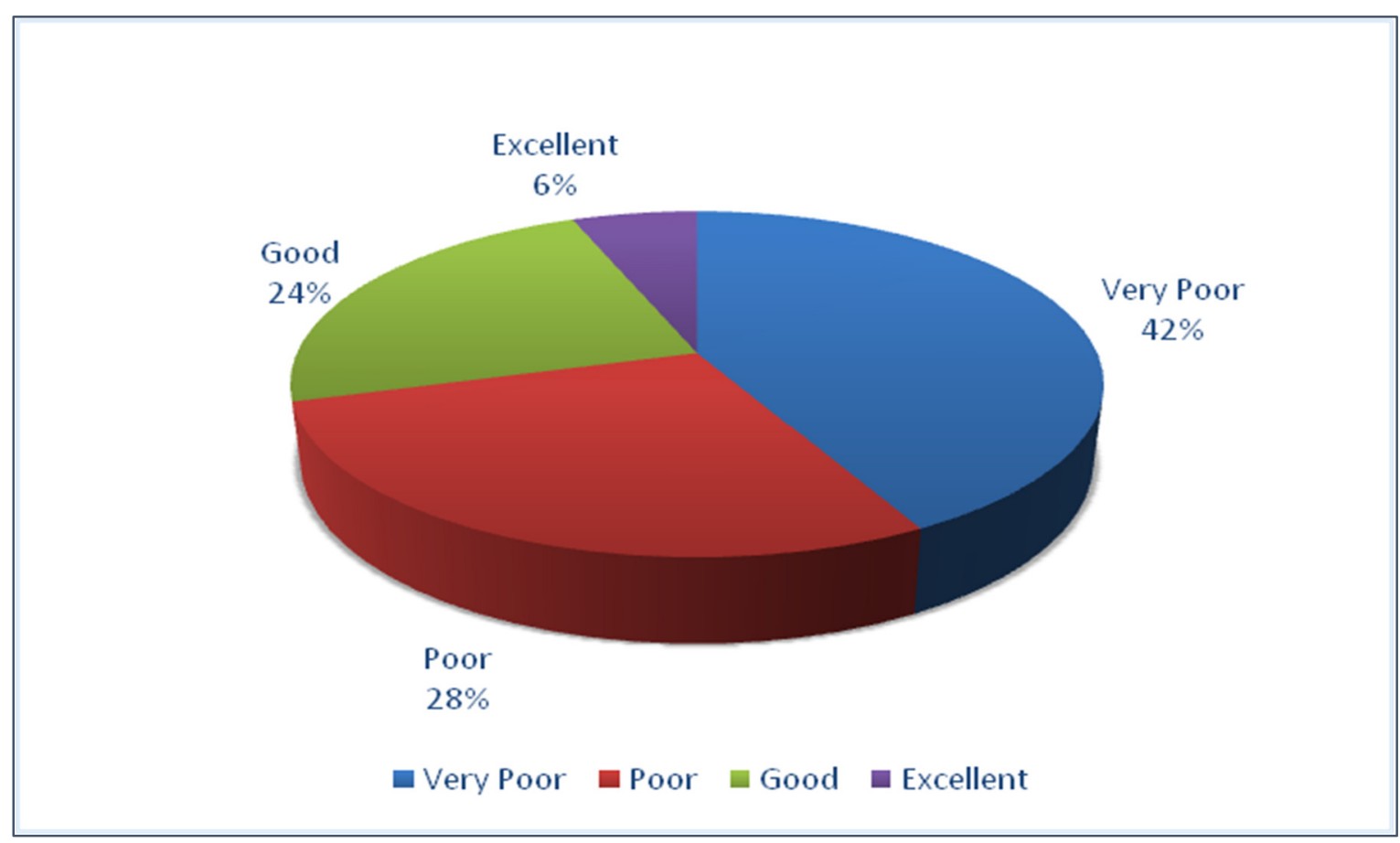

Fig.-2: Chart Representing WQI of Study Area

The correlation matrix in this study was applied using 14 parameters are useful in indicating the relationship between different parameters and the influencing factors. Since, the coefficient of correlation (r) shows the strength of linear relationship between two parameters and varies between -1 to +1 where +1 indicates positive linear relationship while -1 represent negative linear relationship amongst the two parameters. A high and positive correlation were obtained between parameters, such as EC and TDS (0.999), $\mathrm{Cl}^{-}(0.985), \mathrm{NO}_{3}{ }^{-}(0.927), \mathrm{SO}_{4}{ }^{2-}(0.984), \mathrm{Na}^{+}(0.996), \mathrm{K}^{+}(0.978), \mathrm{Mg}^{2+}(0.996), \mathrm{Ca}^{2+}(0.997)$, Total Hardness (0.998) and $\mathrm{HCO}_{3}{ }^{2-}(0.979)$, TDS and $\mathrm{Cl}^{-}(0.985), \mathrm{NO}_{3}^{-}(0.926), \mathrm{SO}_{4}{ }^{2-}(0.984), \mathrm{Na}^{+}(0.996)$, $\mathrm{K}^{+}(0.978), \mathrm{Mg}^{2+}(0.996), \mathrm{Ca}^{2+}(0.997)$, Total Hardness (0.998) and $\mathrm{HCO}_{3}{ }^{2-}(0.979)$. This correlation probably indicates the weathering and erosion of minerals and mining waste present in the area thus increasing the salinity and $\mathrm{EC}$ of the area ${ }^{13}$. The other high positive correlation that exists between $\mathrm{Cl}^{-}$, $\mathrm{NO}_{3}{ }^{-}, \mathrm{SO}_{4}{ }^{2-}, \mathrm{Na}^{+}, \mathrm{K}^{+}, \mathrm{Mg}^{2+}, \mathrm{Ca}^{2+}$, and $\mathrm{HCO}_{3}{ }^{2-}$ are indicative of high pollution from mining, thermal power plants and other industries in form of organic and inorganic pollutants in the area in the vicinity of the reservoir whereas WQI shows highest degree of correlation with $\mathrm{NO}_{3}{ }^{-}$as indicated in Fig.-3, thereby indicating a strong involvement of it in estimating the water quality of the region while the rest of the parameters showed muted relationship in estimating the WQI of the area.

Hierarchical cluster analysis (HCA), another technique of multivariate statistics is defined as an approach to scrutinize the similarity between water quality index of the various sampling sites. The result of HCA is computed in form of Dendrogram. The dendrogram present in the study reveals that site 1 and 2 are having very poor water quality which may conclude the pollution in this area was high while site 3,4 and 7 represents good water quality. Out of 8 sampling sites only one sampling location i.e. site 8 represents excellent water quality which can be useful for domestic or potable consumption and site 5 and 6 falls under poor quality as shown in the Fig.-4. 
RASĀYAN J. Chem.

Vol. 12 | No. 1 |251 - 256| January - March | 2019

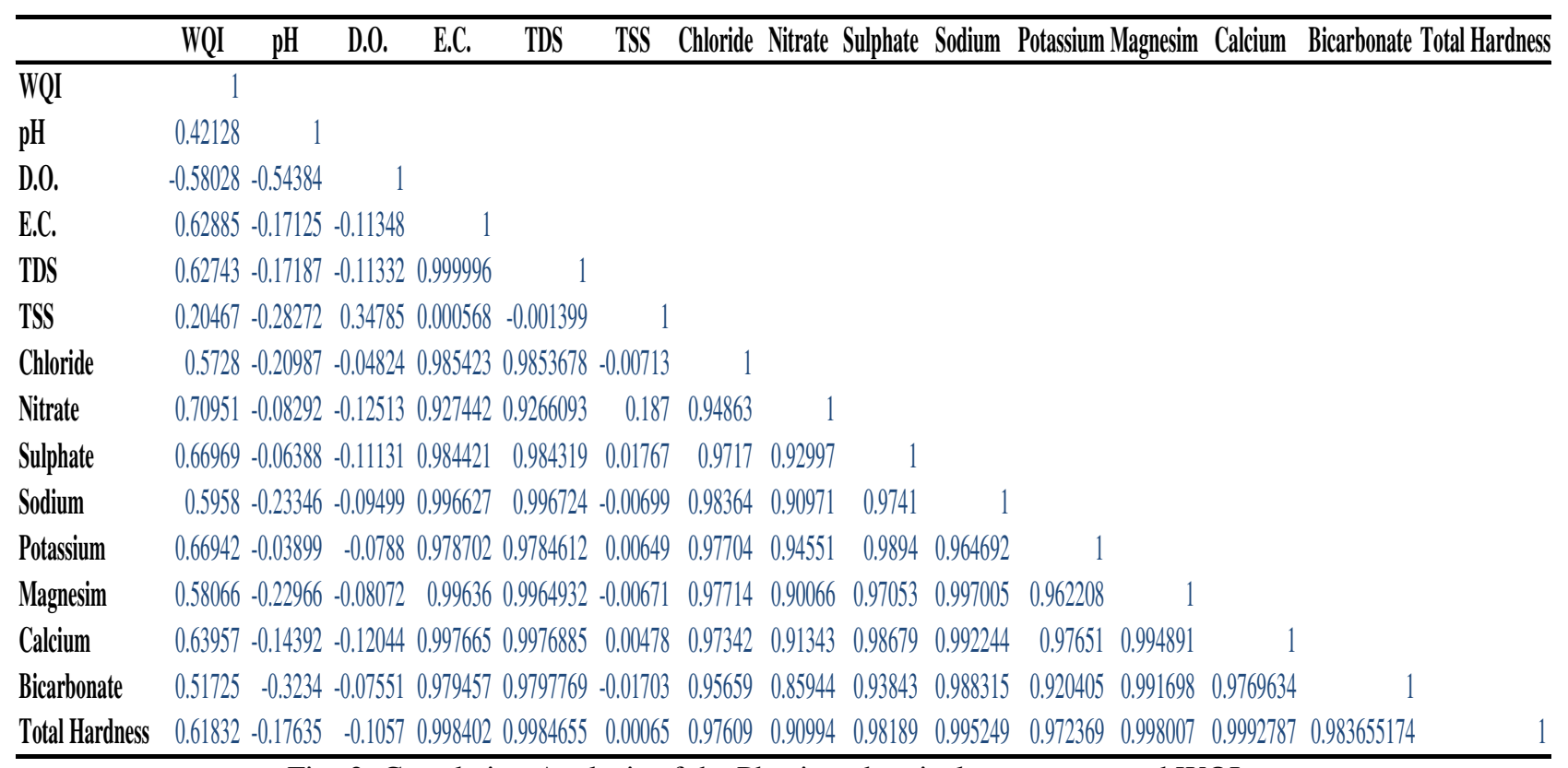

Fig.-3: Correlation Analysis of the Physico-chemical parameters and WQI

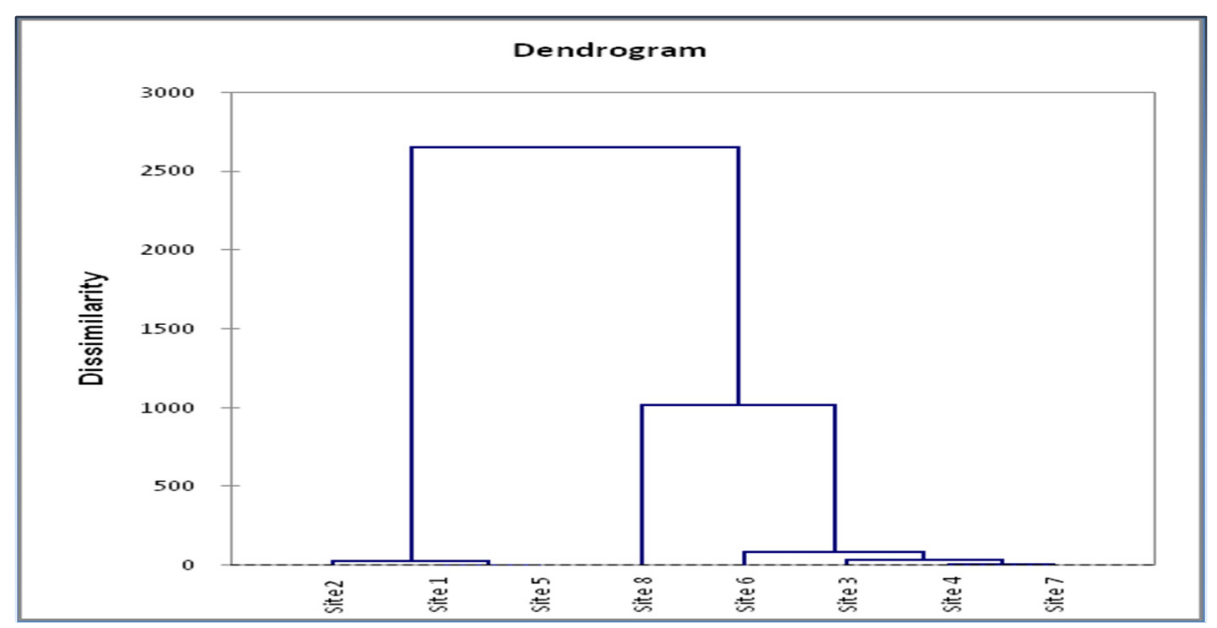

Fig.-4: Dendrogram of Hierarchical Cluster Analysis generated from WQI of the study area

\section{CONCLUSION}

In this study, the physicochemical parameters of G. B. Pant Sagar Reservoir were taken into consideration for the qualitative analysis of the reservoir through the collection of samples. The reservoir is always under stress due to the industrial activity present around it along with the increase of population load over it. The water quality index analysis of the study area reveals that the samples of the reservoir range from excellent to very poor quality i.e. results of WQI indicate that $6 \%$ of reservoir samples fall under excellent, $24 \%$ good, 28\% poor and $42 \%$ under the very poor category. On the basis of the above multivariate statistical approaches as well as WQI of the area under study, it can be concluded that the quality of reservoir water has been significantly deteriorated, therefore an urgent action by government and policy makers are required to combat the negative effect of pollutants added into the reservoir either by natural or artificial processes. It is suggested that the industrial, agricultural or any other anthropogenic practices taking place in the area around the reservoir should be managed properly in order to reduce the pollutant load into the reservoir.

\section{REFERENCES}

1. Z. Du, L. Bin, F. Ling, W. Li, W. Tian, H. Wang, Y. Gui, B. Sun and X. Zhang, Journal of Applied Remote Sensing, 6(1), 063609 (2012), DOI: 10.1117/1.JRS.6.063609. 
RASĀYAN J. Chem.

Vol. 12 | No. 1 | 251 - 256| January - March | 2019

2. J. C. Hower, U. M. Graham, A. S. Wong, J. David Robertson, B. O. Haeberlin, G. A. Thomas, W. H. Schram, Waste Management, 17(8), 533 (1998).

3. M. Dutta, J. Saikia, S. R. Taffarel, F. B. Waanders, D. de Medeiros, C. M. N. L. Cutruneo, L. F. O. Silva, B. K. Saikia, Geoscience Frontiers, 8(6),1297(2017), DOI: 10.1016/j.gsf.2016.11.014.

4. Annual Report2016-17, Government of India, Ministry of Coal, 140 (2017).

5. WHO, Guidelines For Drinking Water Quality, 4th Edition, 631 (2017).

6. Bureau of Indian Standard, Drinking Water- Specification, Second Revision, (2012).

7. F. Ahmad and L. Goparaju, Journal of Geomatics, 11(1), 59(2017).

8. P. Sharma, P. Kachhal, B. Anand, S. Vyas, M. Kaushal, N.V. Mahure, R. Murari, International Journal of Environmental Sciences,3(1), 497 (2012), DOI: 10.6088/ijes.2012030131047.

9. A. K. Sonkar and A. Jamal, Rasayan J. of Chem, 11(3), 276(2018), DOI: 10.31788/RJC.2018.1134026.

10. Ramita Varshney and Aarif Jamal, Rasayan J. of Chem, 11(3), 1182(2018), DOI: 10.31788/RJC.2018.1134023.

11. R.M. Brown, N.I. McClelland, R.A. Deininger and M.F. O'Connor, Indicators of Environmental Quality, 1, 182 (1972), DOI: 10.1007/978-1-4684-2856-8_15.

12. APHA (American Public Health Association), Standard methods for the examination ofwater and wastewater (22 ${ }^{\text {nd }}$ edition), Washington, DC: AWWA, WEF (2012).

13. S. M. Yidana, J. Afr. Earth Sci., 57, 469(2010), DOI: 10.1016/j.jafrearsci.2009.12.002.

14. C. Chatterjee and M. Raziuddin, Nature Environment and Pollution Technology, 1(2), 189 (2002).

15. J. H. Kim, R. H. Kim, J. Lee and H. W. Chang, Environ. Geol. 44, 489(2003).

[RJC-5056/2018] 